\title{
O PODER DE DISPOSIÇÃO NAS RELAÇÕES FAMILIARES E A MEDIAÇÃO COMO MEIO DE ASSEGURAR O DIREITO A CONVIVÊNCIA FAMILIAR
}

\section{Rose Melo Vencelau Meireles ${ }^{1}$}

\section{Resumo}

O poder de disposição, entendido como exercício das situações subjetivas em geral, encontra espaço também nas relações familiares. Nesse sentido, mostra-se lícito regular autonomamente vários dos efeitos insertos na família, a exemplo da prestação alimentar, do modelo de guarda e regime de convivência dos filhos, o cuidado com idosos etc. No âmbito da convivência familiar entre pais e filhos, faz-se necessário promover comportamentos ativos daqueles que integram a família. Por vezes, a alienação parental e o abandono afetivo obstam a convivência familiar saudável, em prejuízo do interesse do menor. Nesses casos, o ordenamento dispõe de instrumentos punitivos e promocionais. A mediação constitui meio adequado para se promover o diálogo no interior das famílias a fim de se propiciar comportamentos ativos com vistas à garantir o direito à convivência familiar. A Lei nº 13.140/2015, que regula a mediação, admite que direitos disponíveis ou indisponíveis transacionáveis sejam objeto de mediação. Critério que se sugere para verificar se a matéria pode ser objeto de mediação consiste na existência de várias opções possíveis, sobre as quais os interessados podem chegar ao consenso, ainda que a homologação judicial se mostre necessária para formação de título executivo. Ademais, a finalidade precípua da mediação se relaciona à restauração do diálogo, sendo o acordo apenas eventual consequência. Nessa medida, a mediação constitui meio adequado para a promoção da convivência familiar, efetiva, saudável e sustentável.

Palavras-chave: Poder de disposição, família, alienação parental, abandono afetivo, mediação

\footnotetext{
${ }^{1}$ Doutora em Direito Civil (UERJ), Professora Adjunta de Direito Civil da Universidade do Estado do Rio de Janeiro. E-mail: rmvmeireles@gmail.com
} 
Cada dia que vivo, mais me convenço de que o desperdício da vida está no amor que não damos, nas forças que não usamos, na prudência egoísta que nada arrisca, e que, esquivando-se do sofrimento, perdemos também a felicidade. A dor é inevitável. O sofrimento éopcional. Carlos Drummond de Andrade.

\section{INTRODUÇÃO}

As situações existenciais, dentre as quais as que configuram as relações familiares, são diferenciadas das situações patrimoniais, sobretudo, para não thes aplicar a normativa própria destas. Nesse sentido, costuma-se qualificar as situações suscetíveis de avaliação econômica como disponíveis, no sentido de que são alienáveis, transmissíveis e renunciáveis, além de prescritíveis, não já as situações existenciais.

Ocorre que, mesmo nas situações patrimoniais, essa disponibilidade se excepciona várias vezes, por exemplo, nas obrigações intuitu personae, nas quais a situação jurídica é incindível ao seu titular, o que veda a transmissibilidade, ou na propriedade gravada com cláusula de inalienabilidade, a qual impooe uma impossibilidade jurídica à alienação etc. E também quanto às situações existenciais existem exceções que permitem a sua disponibilidade, mesmo na acepção acima mencionada, por exemplo, nos transplantes de órgãos, tecidos e partes do corpo humano, de previsão expressa na Lei no. 9.434/1997.

Essa noção de disponibilidade não corresponde ao que se entende por "poder de disposição", aspecto do exercício pleno de qualquer situação jurídica subjetiva. Contudo, cada situação jurídica vai ter um âmbito próprio para expressão desse poder de disposição, o qual está diretamente ligado à atuação da autonomia privada na situação respectiva.

A Lei no 13.140/2015, que dispõe a respeito da mediação entre particulares como meio de solução de controvérsias, trouxe à tona a discussão acerca da qualificação de uma situação jurídica como disponível ou indisponível. Isto porque prevê em seu art. $3^{\circ}$ que pode ser objeto de mediação o conflito que verse sobre direitos disponíveis ou sobre direitos indisponíveis que admitam transação.

Maria e José, após casamento de dois anos, desejam por fim a relação familiar, mas não encontram consenso sobre a partilha dos bens. Trata-se de típico exemplo no qual se identifica a disponibilidade dos direitos envolvidos. No entanto, se Maria e José possuem um filho e discordam a respeito do regime de convivência, não resta evidente a sua disponibilidade. A existência de um poder de disposição, sobre alimentos, convivência, visita de avós, mudança de nome, etc., mostra-se determinante para que o caso possa ser objeto de mediação.

Assim, a seguir será analisado o poder de disposição nas situações existenciais e familiares com o fim de construir base teórica a nortear sua qualificação como disponível, indisponível ou indisponível e transacionável. 


\section{NOTAS SOBRE O PODER DE DISPOSIÇÃO E A QUALIFICAÇÃO DOS DIREITOS DISPONÍVEIS}

O poder de disposição é um dos atributos da propriedade. O art. 1.228, do Código Civil, prescreve que "O proprietário tem a faculdade de usar, gozar e dispor da coisa, e o direito de reavê-la do poder de quem quer que injustamente a possua" (grifou-se). De acordo com Washington de Barros Monteiro, a respeito dos elementos constitutivos da propriedade - direitos de usar, gozar e dispor dos bens - , "O direito de dispor, o mais importante dos três, consiste no poder de consumir a coisa, de aliená-la, de gravá-la de ônus e de submete-la ao serviço de outrem" (MONTEIRO, 1997, p. 85). Os contratos e o testamento são os principais instrumentos do poder de disposição nestes termos considerado. Não é só, pois o poder de disposição também faz parte da atividade empresarial. "O poder de disposição, visto no sentido de escolha da delimitação a ser dada ao bem, adquire uma relevância especial, principalmente pela sua atualidade, enquanto constitui a confluência entre o problema das situações estaticamente consideradas e a iniciativa econômica: o proprietário que se põe o problema da destinação a ser dada a um bem não é somente proprietário, mas é, também empresário" (PERLINGIERI, 1997, p. 223).

Por este começo parece límpida a ligação entre o poder de disposição e o patrimônio em sentido estrito, isto é, constituído de bens valoráveis economicamente. É preciso saber se este poder de disposição é exclusivo do proprietário ou se tem incursões também na categoria do ser. Afinal, a pessoa pode ser tutelada enquanto tem ou enquanto é. No primeiro caso, tem-se as categorias do ter, com a proteção do proprietário, do contratante, do testador etc. No segundo caso, tem-se as categorias do ser, nas quais a pessoa é o centro de interesse, independentemente do seu patrimônio.

As situações existenciais integram as relações jurídicas não patrimoniais que tem como referencial objetivo a própria pessoa. Por isso, pertencem às categorias do ser. Há, portanto, coincidência do elemento subjetivo e do elemento objetivo da relação jurídica. Nesse sentido, afirma-se que quando o objeto de tutela é a pessoa, a perspectiva deve mudar: a pessoa é ao mesmo tempo o sujeito titular do direito e o referencial objetivo da relação. (FEMIA; PERLINGIERI, 2000, p. 119). A perspectiva deve mudar em comparação com as situações patrimoniais porque não há uma distância entre o sujeito e o interesse da relação, como nas situações patrimoniais, nas quais o objeto é externo ao sujeito.

O poder de disposição geralmente é associado à disciplina das situações patrimoniais, sobretudo, conforme foi assinalado acima, à concernente ao direito de propriedade. As situações patrimoniais, ou seja, aquelas suscetíveis de avaliação econômica, seriam disponíveis, isto é, alienáveis, transmissíveis e irrenunciáveis; enquanto que as situações existenciais se submeteriam à disciplina oposta. 
A concepção de "poder de disposição", porém, é muito mais ampla. O poder de disposição compreende uma das formas de exercício das situações jurídicas subjetivas. O exercício das situações jurídicas se configura como o conjunto de comportamentos referentes a elas. Para estes autores, são três os perfis (ou momentos) logicamente e cronologicamente sucessivos das situações jurídicas subjetivas: a existência, a titularidade e o exercício. Uma situação jurídica existe quando há um fato jurídico com eficácia constitutiva: do fato nasce a relação jurídica da qual faz parte a situação. A titularidade é a ligação entre a situação subjetiva e o sujeito, de modo que a titularidade pressupõe a existência da situação e o exercício, geralmente, a titularidade (FEMIA; PERLINGIERI, 2000, p. 133).

O exercício consiste na realização dos interesses do titular da situação jurídica subjetiva a partir dos vários comportamentos referentes a ela. Contudo, para que um comportamento seja qualificado como exercício deve estar de acordo com a função da situação exercida, com os valores que aquela situação deve realizar na hipótese concreta (FEMIA; PERLINGIERI, 2000, p. 133). Na realização dos interesses, o titular da situação jurídica subjetiva ou um sujeito diverso, mas legitimado para o exercício por força de lei ou por convenção, poderá determinar a produção de certos efeitos: constitutivos, modificativos ou extintivos. Não existem outros efeitos além destes fundamentais, de maneira que qualquer outro será reconduzido a eles. As outras "espécies", às vezes utilizadas, são redutíveis às três fundamentais: assim os efeitos de acertamento, regulamentares, normativos, preclusivos, de qualificação (de pessoas, coisas ou fatos) (FEMIA; PERLINGIERI, 2000, p. 103). Isto é poder de disposição: o poder de regular seus próprios interesses determinando efeitos constitutivos, modificativos e extintivos nas situações subjetivas.

A autonomia privada, na sua acepção técnica, coincide com o próprio poder de disposição, como "verdadeiro poder jurídico particular de criar, modificar ou extinguir situações jurídicas próprias ou de outrem" (AMARAL, 2003, p. 348).

Sendo assim, nas searas nas quais a autonomia privada incide, o poder de disposição não pode faltar. No entanto, justamente no âmbito das situações existenciais nem sempre é reconhecida a presença da autonomia privada. Nessa direção, em doutrina identifica-se autonomia privada e poder de disposição, mas os rejeita em algumas situações, como nos direitos da personalidade, nas relações de filiação, no vínculo conjugal, e, em geral, em todos os status de direito de família (FERRI, 1959, p. 225).

Com maior razão, defende-se que a centralidade, no vigente sistema jurídico, da pessoa humana, e assim a emersão de tantos novos aspectos não patrimoniais da mesma, tornam criticável a reconstrução exclusivamente no aspecto patrimonial dos atos de autonomia (PERLINGIERI, 2000, p. 455). Também no ordenamento jurídico brasileiro a pessoa humana possui valor central. $\mathrm{O}$ art. 10, III, da Constituição Federal é verdadeira cláusula geral de tutela e promoção da pessoa humana (TEPEDINO, 2004, p. 50). Como corolário, seria incoerente a 
negação da autonomia privada nas situações existenciais. Ao contrário, percebe-se uma tendência a um incremento dessa autonomia (FRANCO, 2006, p. 156).

A questão, no entanto, não é meramente quantitativa. Dito de outro modo, não houve uma redução da autonomia nas situações patrimoniais e um aumento nas situações existenciais. Há situações existenciais cujo poder de disposição, se não é nulo é bastante reduzido. O poder de disposição, tanto nas situações patrimoniais, quanto nas existenciais, para ser digno de tutela, deve estar adequado à função da situação jurídica subjetiva correspondente. Essa funcionalização das situações jurídicas opera internamente e não externamente, razão pela qual se entende que o critério delimitador do trânsito da autonomia privada em determinada situação subjetiva não deve ser o quantitativo e sim o qualitativo.

Conforme foi antes aduzido, nas situações existenciais o referencial objetivo não é externo como o é nas situações patrimoniais. Esta característica impõe que o poder de disposição nas situações existenciais tenha disciplina diversa em relação às situações patrimoniais. É por isso que, via de regra, as situações existenciais são intransmissíveis e irrenunciáveis. Ocorre que a transmissão e a renúncia são apenas aspectos do poder de disposição que compreende uma série de outros efeitos.

Nas relações familiares o poder de disposição também está presente, muito embora com características próprias correlatas a diversidade de função das diversas situações subjetivas que compõe a complexidade desse tipo de relação (MEIRELES, 2008, passim).

\section{O PODER DE DISPOSIÇÃO NAS RELAÇÕES FAMILIARES}

O emprego da consolidada noção de autonomia privada nas relações familiares, segundo a qual, é o poder reconhecido ou atribuído ao particular para disciplinar os próprios interesses, é inadequado. Isto porque na seara do direito de família, esse poder foi atribuído ao particular para autorregular não apenas interesses próprios, isto é, de exclusiva pertinência a cada um, mas, também, interesses comuns, aos quais os primeiros devem se reportar e com os quais devem realizar um clima de harmônico temperamento (DONISI, 1997, pp. 498-499).

É verdade que a família, se for considerada como entidade intermédia, poderá ser produtora de uma autonomia comunitária. Trata-se da autonomia familiar, a qual tem um prisma externo para garantir frente ao Estado a liberdade de uma peculiar comunidade intermédia; e um prisma interno no qual a liberdade é assegurada dentro da família, como um lugar em que os componentes podem levar os seus problemas e buscar a melhor solução. A esse respeito, afirma-se em doutrina que "Com a prevalência da cultura pluralista, a atenção concentrase quase que exclusivamente nos problemas internos do grupo, na determinação dos conteúdos das situações subjetivas de cada um" (PERLINGIERI, 1997, p. 283). 
De fato, tomando-se por base uma concepção funcionalizada, na qual a família não é um instituto que se basta em si mesmo, mas tem a precípua função de assegurar o livre desenvolvimento dos seus membros, os fins comuns de per se não podem servir de empecilho para que um componente em particular busque a sua dignidade. Existem interesses individuais e interesses coletivos que devem ser ponderados em cada situação concreta. Assim, por exemplo, não se pode impedir a perfilhação somente porque o filho foi concebido fora do casamento; não se pode impor que os pais amem e cuidem dos seus filhos biológicos, permitindo-se a adoção; nem se pode impor um casamento indissolúvel. Por isso, o poder de disposição, ainda que com um conteúdo diverso daquele encontrado nas situações patrimoniais, também existe nas relações familiares. E é justamente nesse poder de disposição que, muitas das vezes, a pessoa encontra o meio de se desenvolver livremente, mesmo que para isso tenha que produzir efeitos modificativos e até extintivos no interior da família.

\section{DIREITOS INDISPONÍVEIS TRANSACIONÁVEIS E A LEI DE MEDIAÇÃO}

A Lei no 13.140, de 26 de junho de 2015, passou a regular a mediação, "atividade técnica exercida por terceiro imparcial sem poder decisório, que, escolhido ou aceito pelas partes, as auxilia e estimula a identificar ou desenvolver soluções consensuais para a controvérsia”, conforme o conceito legal.

O Projeto de Lei no 517/2011 não restringia o objeto da mediação. O Projeto de Lei no 7.169/2014, a seu turno, limitava o objeto da mediação a matérias que admitissem transação, sem adentrar na qualificação da situação jurídica como disponível ou indisponível. A redação do art. $3^{\circ}$ da Lei de Mediação, contudo, refere-se a direitos disponíveis e indisponíveis transacionáveis, ao prever que "pode ser objeto de mediação o conflito que verse sobre direitos disponíveis ou sobre direitos indisponíveis que admitam transação".

Nas relações familiares o poder de disposição, como forma de exercício das situações subjetivas relacionadas, encontra variáveis medidas conforme a autonomia privada possua maior ou menor espaço para o livre desenvolvimento da pessoa. Os direitos patrimoniais referentes a partilha de bens em caso de divórcio ou direitos existenciais como a manutenção do nome de casado após o divórcio, por exemplo, inserem-se em um espaço de escolha, de autonomia, dos titulares. Outros direitos patrimoniais, como o direito a alimentos, ou direitos existenciais, a exemplo do poder familiar, situam-se fora desse campo. Assim, não se trata tão somente de qualificar os direitos em patrimoniais ou existenciais. Importa sim verificar nas relações familiares a presença do poder de disposição.

O critério a ser utilizado, portanto, para submeter a controvérsia à mediação, consiste na existência de duas ou mais soluções possíveis para o caso. Trata-se do acima referido "poder de disposição, visto no sentido de escolha da delimitação a ser dada ao bem" (PERLINGIERI, 1997, p. 223). Quando presente o valor da liberdade 
de escolha, cabível a mediação como método de solução de impasses. Nesse sentido a expressão "direitos indisponíveis transacionáveis", eis que sendo suscetível de transação o direito se mostra aberto à autonomia, de modo que essa categoria de direitos configura verdadeira contradição em termos, segundo a teoria aqui acolhida a respeito do poder de disposição como exercício das situações subjetivas. Assim, releva verificar a possibilidade jurídica de escolhas a respeito do direito (ou situação) para que este seja objeto de mediação.

O Projeto de Lei $n^{\circ} 7.169 / 2014$ estabelecia no $₫ 3^{\circ}$ do art. $3^{\circ}$ que não podia ser objeto de mediação o conflito que tratasse de filiação, adoção, poder familiar, invalidade do matrimônio e interdição. Muito embora a Lei de Mediação não tenha mantido essa previsão específica, pode-se observar que são matérias com raso espaço para autonomia privada.

O conceito indeterminado de "direitos indisponíveis transigíveis" encontra ainda interesse prático porque o art. $3^{\circ}, \$ 2^{\circ}$ da Lei de Mediação estabelece que "o consenso das partes envolvendo direitos indisponíveis, mas transigíveis, deve ser homologado em juízo, exigida a oitiva do Ministério Público". Significa dizer que o eventual acordo resultante da mediação, no caso de "direitos indisponíveis", depende de homologação judicial para valer como título executivo.

A Lei de Mediação adota a classificação dos direitos disponíveis e indisponíveis não pelo critério da autonomia privada. $\mathrm{O}$ art. $3^{\circ}, \$ 2^{\circ}$ citado, indica que matérias de ordem pública, entendidas como aqueles voltadas também para interesses comunitários, não apenas individuais, devam ser submetidas ao controle do Ministério Público e do Judiciário.

Nas relações familiares, as hipóteses que dispensam a intervenção do Judiciário, tais como divórcio e inventário extrajudicial, submetem-se à mediação sem a necessidade de homologação judicial. Quando a mediação envolver interesses de menor ou incapazes, a eficácia executiva do eventual acordo realizado dependeria de homologação judicial. Casos referentes à convivência familiar, por envolver interesse de menor, requerem a homologação judicial do termo de acordo realizado em mediação, por exemplo.

\section{O DIREITO A CONVIVÊNCIA FAMILIAR, A ALIENAÇÃO PARENTAL E O ABANDONO AFETIVO}

O direito à convivência familiar tem previsão constitucional no art. 227, caput, ao enunciar que "É dever da família, da sociedade e do Estado assegurar à criança, ao adolescente e ao jovem, com absoluta prioridade, o direito à vida, à saúde, à alimentação, à educação, ao lazer, à profissionalização, à cultura, à dignidade, ao respeito, à liberdade e à convivência familiar e comunitária, além de colocá-los a salvo de toda forma de negligência, discriminação, exploração, violência, crueldade e opressão" (grifou-se). O direito à convivência familiar também se 
encontra no Estatuto da Criança e do Adolescente, como instrumento de garantia ao desenvolvimento integral da pessoa. Nesse diploma legislativo, trata-se do exercício da convivência familiar no âmbito da família natural e da família substituta. A convivência dos filhos com os pais, após a o fim da relação do casal é definida por meio do instituto da guarda, disciplinada no artigo 1.583 e seguintes do Código Civil.

Dentre as modalidades de guarda, o legislador confere a faculdade de se estabelecer a guarda unilateral ou compartilhada. Dispõe o $\$ 2^{\circ}$ do art. 1.584 , que "quando não houver acordo entre a mãe e o pai quanto à guarda do filho, encontrando-se ambos os genitores aptos a exercer o poder familiar, será aplicada a guarda compartilhada, salvo se um dos genitores declarar ao magistrado que não deseja a guarda do menor". Significa dizer que tanto o consenso, quanto o dissenso, podem levar à guarda compartilhada. Presume-se que esse modelo de convivência familiar melhor atende ao interesse da criança, embora somente o caso concreto possa confirmar tal conclusão. A falta de consenso pode, de fato, prejudicar a guarda compartilhada como modelo que melhor atenda ao interesse da criança. Nesses casos, poderá o juiz decidir a convivência de modo diverso, estabelecendo a guarda unilateral a um dos pais ou deferir a guarda aos avós, por exemplo.

Independentemente da modalidade de guarda estabelecida, o direito à convivência familiar pode vir a ser frustrado pela ocorrência de alienação parental. $\mathrm{O}$ art. $2^{\circ}$ da Lei no $12.318 / 2010$ prevê que se considera "ato de alienação parental a interferência na formação psicológica da criança ou do adolescente promovida ou induzida por um dos genitores, pelos avós ou pelos que tenham a criança ou adolescente sob a sua autoridade, guarda ou vigilância para que repudie genitor ou que cause prejuízo ao estabelecimento ou à manutenção de vínculos com este".

Vale estabelecer a diferença entre a alienação parental e a síndrome dela decorrente. A síndrome da alienação parental começou a ser delineada em 1985, pelo psiquiatra infantil Richard Gardner, que a definiu como abuso emocional daquele que exerce o poder parental sobre o infante (GARDNER, 1985, pp. 03-07). Nota-se que nem sempre a prática da alienação parental culmina no desenvolvimento da síndrome, vez que depende de uma série de fatores tais como a idade da criança e o grau de alienação que é praticado (FONSECA, 2006, p. 06). Ocorre que nos casos em que a síndrome de fato se instala e a criança passa a oferecer resistência a figura do genitor vítima da alienação, o restabelecimento da convivência durante a infância apenas é possível em cerca de 5\% dos casos (FONSECA, 2006, p. 03), ou seja, é extremamente importante que o processo de alienação seja interrompido o quanto antes a fim de possibilitar que a convivência entre os entes familiares não seja prejudicada, e que a criança não chegue a desenvolver a síndrome que tem uma série de efeitos psicológicos com registros até na vida adulta.

A Lei de Alienação Parental refere-se ao direito à convivência familiar saudável, pois a prática da alienação parental, não obstante a regulamentação da guarda, ocasiona a quebra do afeto. "Como encontros impostos de 
modo tarifado não alimentam o estreitamento dos vínculos afetivos, a tendência é o arrefecimento da cumplicidade que só a convivência traz. Afrouxando-se os elos de afetividade, ocorre o distanciamento, tornando as visitas rarefeitas. Com isso, os encontros acabam protocolares: uma obrigação para o pai e, muitas vezes, um suplício para os filhos" (GARDNER, 1985, pp. 03-07).

Muito embora a própria lei sugira o uso de perícia psicológica ou biopsicossocial quando houver indício de alienação parental, demonstrando a necessária multidisciplinariedade no tema, muitas vezes os estudos sociais e psicológicos não são conclusivos, cabendo ao juiz decidir de acordo com o princípio do melhor interesse da criança. Nessa direção, o artigo 7o da Lei de Alienação Parental fixa um critério de preferência na atribuição ou alteração da guarda, para o genitor que viabiliza a efetiva convivência da criança ou adolescente com o outro genitor nas hipóteses em que seja inviável a guarda compartilhada.

Sem prejuízo da decorrente responsabilidade civil ou criminal e da ampla utilização de instrumentos processuais aptos a inibir ou atenuar seus efeitos, cabem as seguintes sanções pela prática de alienação parental, segundo a gravidade do caso, previstas no artigo $6^{\circ}$ da Lei no 12.318/2010:

\footnotetext{
I- declarar a ocorrência de alienação parental e advertir o alienador;

II - ampliar o regime de convivência familiar em favor do genitor alienado;

III - estipular multa ao alienador;

IV - determinar acompanhamento psicológico e/ou biopsicossocial;

V - determinar a alteração da guarda para guarda compartilhada ou sua inversão;

VI - determinar a fixação cautelar do domićlio da criança ou adolescente;

VII - declarar a suspensão da autoridade parental.
}

Uma das consequências da alienação parental, embora possa ocorrer independentemente dela, consiste no abandono afetivo. Um dos pais aliena e o outro abandona, criando um círculo perverso contra o interesse do filho. O dever de cuidado cabe aos pais, conjuntamente, independentemente do modelo de guarda. Trata-se do dever de prover todos os direitos constitucionais da criança estabelecidos em síntese no art. 227, caput, da Constituição da República. O não cumprimento desse dever caracteriza o abandono, material, intelectual ou afetivo. $\mathrm{O}$ abandono material ocorre quando se deixa de prover a subsistência do menor sem justa causa. $\mathrm{O}$ abandono intelectual se verifica quando se deixa de garantir a educação fundamental sem justa causa. E o abandono afetivo se caracteriza pela ausência do convívio familiar saudável.

O art. 1.638 do Código Civil estabelece como sanção para o pai ou mãe que deixa o filho em abandono a perda do poder familiar, por ato judicial. Discute-se também a reparação civil por dado causado em virtude de abandono afetivo.

Desse modo, mostra-se marcante a lógica punitiva, sancionatória, a regular as hipóteses de alienação parental e abandono afetivo. Entretanto, tutela sancionatória não se mostra suficiente para tutelar a pessoa, sobretudo a pessoa em desenvolvimento nas relações familiares. Nesse sentido, Gustavo Tepedino afirma que: 
Nem parece suficiente o mecanismo simplesmente repressivo, próprio do direito penal, de incidência normativa limitada aos momentos patológicos das relações jurídicas, no momento em que ocorre a violação do direito, sob a moldura das situações-tipo. A tutela da pessoa humana, além de superar a perspectiva setorial (direito público e direito privado), não se satisfaz com as técnicas ressarcitória e repressiva (binômio sanção-lesão), exigindo, ao reverso, instrumentos de promoção do homem, considerado em qualquer situação jurídica de que participe, contratual ou extracontratual, em direito público ou em direito privado (TEPEDINO, 2004, p. 46).

O valor da pessoa humana não se realiza automaticamente, mas com uma série de comportamentos conformes, de modo que o dever de abstenção não exaure a relevância da pessoa no universo normativo (SCALISI, 1990, p. 74-75). Do mesmo modo que na esfera patrimonial se encontra respaldo jurídico também no exercício da faculdade de contratar, testar etc., nas situações existenciais a autonomia privada pode ser elemento útil ao pleno desenvolvimento da personalidade, conferindo-lhes uma tutela positiva. A liberdade positiva identifica-se assim com a autodeterminação. "Diz-se que ela é positiva, porque pressupõe que o indivíduo reúna as condições necessárias para agir, não se esgotando na mera ausência de impedimentos externos, ao contrário da liberdade negativa" (SARMENTO, 2006, p.148).

A tutela positiva das situações jurídicas existenciais permite que a autonomia privada possa ser também instrumento de regulação de interesses existenciais, a fim de garantir o livre desenvolvimento do seu titular (MEIRELES, 2009, pp. 53-61). É chamada positiva porque realizada mediante a autodeterminação do titular, muitas vezes, com colaboração de outrem; enquanto que a tutela negativa diz respeito a comportamentos omissivos gerais, os quais têm repercussão jurídica apenas depois da lesão. Nesse sentido o poder de disposição se apresenta também nas relações familiares. A autonomia privada é aqui considerada como meio para se conferir uma proteção positiva às situações subjetivas. Por intermédio dela, a pessoa, para garantir o livre desenvolvimento da sua personalidade, poderia se autodeterminar, ou seja, criar, modificar ou extinguir situações subjetivas, conforme fosse o efeito mais adequado para a tutela da pessoa, inclusive nas relações familiares.

Com efeito, a personalidade não se exaure no aspecto negativo (dever de abstenção), uma vez que ao lado de uma situação ativa que o direito caracteriza pelo comportamento negativo dos outros (não me atingir: situação passiva é o dever geral de abstenção), a personalidade é valor que se obtém também positivamente, como fundamento de situações subjetivas ativas que requerem dos outros não uma abstenção (comportamento omissivo), mas a cooperação (comportamento ativo) na realização de um interesse existencial (FEMIA; PERLINGIERI, 2000, p. 120).

A garantia do direito à convivência familiar requer, assim, comportamentos ativos das pessoas que integram a família nuclear e extensa. A lógica reparatória não restabelece os laços de afeto rompidos em razão da 
alienação parental ou abandono afetivo. Desse modo, não promove a dignidade da pessoa no âmbito familiar. Nesse cenário, a mediação constitui caminho válido a promoção da convivência familiar, direito fundamental da criança, do adolescente e do jovem.

\section{A MEDIAÇÃO COMO INSTRUMENTO DE PROMOÇÃO DA CONVIVÊNCIA FAMILIAR}

O Código de Processo Civil visa a realizar, no plano processual, o princípio da mínima intervenção estatal na família. Por conseguinte, a intervenção do Estado nas relações familiares passa a ser funcionalizada à proteção dos membros da família e da concessão de garantias quanto ao direito da personalidade de cada um deles. Os limites da autonomia privada nas relações familiares, entretanto, constitui matéria em construção (FERRAJOLI, 1993, passim).

O art. $9{ }^{\circ}$ da Lei de Alienação Parental, que previa expressamente a mediação, por exemplo, fora vetado:

Art. 9ำAs partes, por iniciativa própria ou sugestão do juiz, do Ministério Público ou do Conselho Tutelar, poderão utilizar-se do procedimento da mediação para a solução do litígio, antes ou no curso do processo judicial.

\ $1^{\circ} \mathrm{O}$ acordo que estabelecer a mediação indicará o prazo de eventual suspensão do processo e o correspondente regime provisório para regular as questōes controvertidas, o qual não vinculará eventual decisão judicial superveniente.

\ $2^{\circ} \mathrm{O}$ mediador será livremente escolhido pelas partes, mas o juízo competente, o Ministério Público e o Conselho Tutelar formarão cadastros de mediadores habilitados a examinar questões relacionadas à alienação parental.

$\$ 3^{\circ}$ O termo que ajustar o procedimento de mediação ou o que dele resultar deverá ser submetido ao exame do Ministério Público e à homologação judicial.

Nas razões para o veto, seguiu a seguinte justificativa:

O direito da criança e do adolescente à convivência familiar é indisponível, nos termos do art. 227 da Constituição Federal, não cabendo sua apreciação por mecanismos extrajudiciais de solução de conflitos.

Ademais, o dispositivo contraria a Lei no 8.069, de 13 de julho de 1990, que prevê a aplicação do princípio da intervenção mínima, segundo o qual eventual medida para a proteção da criança e do adolescente deve ser exercida exclusivamente pelas autoridades e instituições cuja ação seja indispensável.

A justificativa do veto também assume a lógica punitiva empregada para a situação da alienação parental.

Ocorre que a mediação segue a lógica promocional. Este o escopo da mediação familiar:

(...) um método que visa não apenas tratar o conflito, mas preservar a família em crise, ou seja, preservar sua formação como ente voltado ao afeto, à verdade, à igualdade. Assim, ela busca restabelecer o vínculo familiar após a ruptura conjugal, pelo diálogo (MARCANTÔNIO, Roberta; WUST, 2013, p. 09).

Como se sabe, a resolução da lide nem sempre põe fim ao conflito familiar. Isto porque o modelo heterocompositivo não atua na barreira cognitiva do conflito, ligada à capacidade das pessoas em processar 
informações e lidar com riscos e incertezas (COSTA FILHO, 2004, p. 107). Por esse motivo, considera-se a mediação o método mais adequado para a solução de litígios envolvendo interessados que possuem um relacionamento pessoal, duradouro e continuado, como nas relações familiares (HILL, 2015, p. 190).

Dessa forma, a mediação se configura como instrumento hábil para a promoção do direito à convivência familiar. A participação ativa dos interessados na construção do modelo de convivência familiar mais adequado para o seu caso contribui positivamente para que os arranjos familiares atendam ao melhor interesse da criança. E a consequência, se bem sucedida a mediação, e com apoio multidisciplinar, pode ser a reconstrução do afeto.

\section{PARA CONCLUIR}

A garantia à convivência familiar somente pode ser efetivada a partir de instrumentos que promovam comportamentos ativos daqueles que integram a família. A lógica repressiva, punitiva ou reparatória também constitui aspecto importante da tutela das situações subjetivas, quando violadas. Contudo, no âmbito das relações familiares, que deveriam ser duradouras e continuadas, a lógica promocional se apresenta mais apta a atender a função da família como meio de desenvolvimento da personalidade de seus membros.

Nesse contexto, a Lei no 13.140/2015 admite que direitos indisponíveis sejam objeto de mediação. Muito embora se entenda que o poder de disposição também está presente nas relações familiares, mesmo quando há também intervenção estatal, para a mediação importa que seja matéria transacionável. Assim, ainda que se qualifique o direito como indisponível, caberá o uso da mediação se for transigivel.

Critério que se sugere para verificar se a matéria pode ser objeto de mediação consiste na existência de várias opções possíveis, sobre as quais os interessados podem chegar ao consenso. Deve-se perguntar: há escolha na delimitação do bem? Cabe registrar que o acordo final na mediação é um resultado possível, mas não necessário. Imagine-se o pai que se afastou da filha, hoje adulta, que utiliza a mediação como instrumento tão somente para resgatar o diálogo e a convivência familiar. A finalidade precípua da mediação se relaciona à restauração do diálogo, sendo o acordo apenas sua eventual consequência. Nessa medida, a mediação constitui sempre instrumento de promoção da convivência familiar, efetiva, saudável e sustentável. 


\title{
THE POWER OF DISPOSITION IN FAMILY RELATIONSHIPS AND THE MEDIATION AS A MEANS OF ENSURING THE RIGHT TO FAMILY LIVING
}

\begin{abstract}
Known as the exercise of subjective general situation, the power of disposition also finds place in family relationships. In this regard, it is possible to regulate autonomously several situations also in family law, such as the provision of food, model of custody and children living regime, care for the elderly etc. In the family relationship context between parents and children, active behaviors of those who are part of the family must be provided. Parental alienation and affective abandonment sometimes interfere with the healthy family life to the detriment of the child's interest. In these cases, the law has punitive and promotional instruments. Mediation is an appropriate means of promoting dialogue within families, in order to foster active behavior to ensure the right to a family life coexistence. Brazilian Law No. 13.140/2015, which governs mediation, acknowledges that available or unavailable tradable rights are subject to mediation. A criterion suggested to verify whether the matter can be mediated is the existence of several possible options, on which the interested parties can reach a consensus, even if a court ratification proves to be necessary for the formation of an enforceable instrument. Moreover, the primary purpose of mediation relates to the restoration of dialogues, with the agreement being only a possible consequence. To that extent, mediation is an appropriate means for promoting effective, healthy and sustainable family coexistence.
\end{abstract}

Keywords: Power of disposition; family, parental alienation, affective abandonment, mediation.

\section{REFERENCIAS BIBLIOGRÁFICAS}

AMARAL, Francisco. Direito Civil. Introdução. Rio de Janeiro: Renovar, 2000.

BERNARDO, Wesley L., Dano moral por abandono afetivo. In FACHIN, Luiz Edson; TEPEDINO, Gustavo (org.). Diálogos sobre direito civil, vol. II. Rio de Janeiro: Renovar, 2008.

COSTA FILHO, Venceslau Tavares. A conciliação e a mediação de conflitos familiars no Código de Processo Civil Brasileiro. Revista Magister de Direito Civil e Processual Civil, vol. 1, jul./ago. 2004. Porto Alegre: Magister, 2004. 
DIAS, Maria Berenice. Síndrome da alienação parental, o que é isso?, 2010, p. 1. Disponível em: http://www.mariaberenice.com.br/artigos.php?subcat=320\#anc. Acesso em: 29 jun. 2017.

DONISI, Carmine. Limiti all'autoregolamentazione degli interessi nel diritto di famiglia. In Rasegna di Diritto Civile, n. 7, 1997.

FEMIA, Pasquale; PERLINGIERI, Pietro. Nozioni Introdutive e Principi Fondamentali del Diritto Civile. Napoli: Edizioni Scientifiche Italiane, 2000.

FERRAJOLI, Luigi. Il diritto privato del futuro: liberta, poteri e garanzie. In: PERLINGIERI, Pietro (org.). Il diritto privato futuro. Napoli: Edizioni Scientifiche Italiane, 1993.

FERRI, Luigi. L'Autonomia Privata. Milano: Giuffrè Editore, 1959.

FONSECA, Priscila Maria Pereira Corrêa da. Síndrome da alienação parental. Pediatria, São Paulo, 2006, p. 6. Disponível em: http://www.wilsoncamilo.org/arquivos/alienacao_parental.pdf. Acesso em: 26 jun. 2017.

FRANCO, Denis da Silva. O Princípio da Autonomia: da Invenção à Reconstrução. In: MORAES, Maria Celina Bodin de. Princípios do Direito Civil Contemporâneo. Rio de Janeiro: Renovar, 2006.

GARDNER, Richard. Recent Trends in Divorce and Custody Litigation. Academy Forum, v. 29, n. 2, Summer, 1985.

GOLDENBERG, Gita Wladimirski, O primado da afetividade e o império da lei: a indenização por abandono afetivo à luz do direito e da psicanálise. In: GUERRA, Carlos Eduardo (coord.). Criança e Adolescente. Rio de Janeiro: Freitas Bastos, 2015.

HILL, Flávia Pereira. A mediação de conflitos no novo Código de Processo Civil e na Lei federal no 13.140/2015. In: MIRZA, Flavio (org.). Direito Processual. Rio de Janeiro: Freitas Bastos, 2015, p. 190.

MARCANTÔNIO, Roberta; WUST, Caroline. A mediação como forma de tratamento dos conflitos decorrentes da alienação parental: uma análise da Lei no 12.318/2010 e o veto ao artigo 9º. Anais do I Seminário 
Internacional de Mediação de Conflitos e Justiça Restaurativa, 2013. Disponível em: http://online.unisc.br/acadnet/anais/index.php/mediacao_e_jr/article/view/10892/1421. Acesso em $22 / 05 / 2017$.

MEIRELES, Rose Melo Vencelau. O poder de disposição nas relações familiares. In: FACHIN, Luiz Edson; TEPEDINO, Gustavo (org.). Diálogos sobre direito civil, vol. II. Rio de Janeiro: Renovar, 2008.

MONTEIRO, Washington de Barros. Curso de Direito Civil, 3º vol. 33ª ed. São Paulo: Saraiva,1997.

MORAES, Maria Celina Bodin de. Danos morais em família? Conjugalidade, parentalidade e responsabilidade civil. In: Na medida da pessoa humana. Rio de Janeiro: Renovar, 2010.

PEREIRA, Rodrigo da Cunha. Indenização por abandono afetivo e material. Revista Brasileira de Direito das Famílias e Sucessões, n. 25, vol. 13. Porto Alegre, Magister, 2011.

PERLINGIERI, Pietro. Manuale di Diritto Civile. $2^{a}$ ed. Napoli: Edizioni Scientifiche Italiane, 2000.

PERLINGIERI, Pietro. Perfis do Direito Civil. Rio de Janeiro: Renovar, 1997.

SARMENTO, Daniel. Direitos Fundamentais e Relações Privadas. 2a ed. Rio de Janeiro: Lumen Juris, 2006.

SCALISI, Antonino. Il Valore della Persona nel Sistema e i Nuovi Diritti della Personalità. Milano: Giuffrè Editore, 1990.

TEPEDINO, Gustavo. A Tutela da Personalidade no Ordenamento Civil-Constitucional Brasileiro. In Temas de Direito Civil. $3^{\mathrm{a}}$ ed. Rio de Janeiro: Renovar, 2004.

Trabalho enviado em 29 de outubro de 2018

Aceito em 29 de outubro de 2018 